This item was submitted to Loughborough's Research Repository by the author.

Items in Figshare are protected by copyright, with all rights reserved, unless otherwise indicated.

\title{
Impact of acute choline loading on circulating trimethylamine $\mathrm{N}$-oxide levels
}

PLEASE CITE THE PUBLISHED VERSION

https://doi.org/10.1177/2047487319831372

PUBLISHER

SAGE Publications $@$ C The European Society of Cardiology

VERSION

AM (Accepted Manuscript)

\section{PUBLISHER STATEMENT}

This work is made available according to the conditions of the Creative Commons Attribution-NonCommercialNoDerivatives 4.0 International (CC BY-NC-ND 4.0) licence. Full details of this licence are available at: https://creativecommons.org/licenses/by-nc-nd/4.0/

\section{LICENCE}

CC BY-NC-ND 4.0

\section{REPOSITORY RECORD}

Cassambai, Shabana, Andrea Salzano, Yoshiyuki Yazaki, Dennis Bernieh, Max Wong, M. Zubair Israr, Liam Heaney, and Toru Suzuki. 2019. "Impact of Acute Choline Loading on Circulating Trimethylamine N-oxide Levels". figshare. https://hdl.handle.net/2134/37063. 


\section{Impact of acute choline loading on circulating trimethylamine N-oxide (TMAO) levels}

Shabana Cassambai ${ }^{1}$, Andrea Salzano ${ }^{1 *}$, Yoshiyuki Yazaki ${ }^{1 *}$, Dennis Bernieh ${ }^{1}$, Max Wong ${ }^{1}$, M Zubair Israr ${ }^{1}$, Liam M Heaney $^{1 \S}$, Toru Suzuki ${ }^{1}$

* These authors contributed equally

\section{Affiliations:}

${ }^{1}$ University of Leicester, Department of Cardiovascular Sciences, Clinical Sciences Wing, Glenfield General Hospital, Leicester, LE3 9QP, UK

$\S$ Present address; School of Sport, Exercise \& Health Sciences, Loughborough University, Loughborough, LE11 3TU, UK

\section{Address for Correspondence:}

Toru Suzuki

Department of Cardiovascular Sciences and NIHR Leicester Cardiovascular Biomedical Research Centre, University of Leicester, Glenfield Hospital, Leicester, LE3 9QP, United Kingdom

Email: ts263@le.ac.uk. Tel: (0044) 1162044741

Word Count: 1038

Key words: Cardiovascular disease; cardiovascular prevention; Trimethylamine N-oxide (TMAO); diet; choline; biomarker 
Despite recent efforts to reduce cardiovascular disease risk by dietary intervention (1), few markers are useful to assess the efficiency and progress of this. Circulating levels of trimethylamine $\mathrm{N}$-oxide (TMAO) are associated with poor outcomes of cardiovascular disease (2-6). TMAO is generated via hepatic flavin monooxygenase 3 (FMO3) mediated oxidation of trimethylamine (TMA) (7), derived largely from carnitine and choline through gut microbial metabolism. These substrates are found in red meat and eggs which are representative of a Western diet. Therefore, TMAO levels could be used to monitor the effect of dietary intervention, particularly for the consumption of a Western diet. In this study, we examined the effect of acute choline loading on TMAO levels in healthy adult volunteers.

Eighteen healthy omnivorous adult volunteers, with no history of recent use of antibiotics/probiotics, completed this study. Baseline characteristics and blood samples were obtained from participants at baseline (BL). Participants were asked to complete a daily written food diary and returned after 2 weeks (visit 2, V2). The consumption of red meat, fish, and eggs was not permitted 24 hours before BL and V2. Prior to taking $700 \mathrm{mg}$ of choline bitartrate capsules (Solgar, USA), a blood sample was collected to measure TMAO level at time zero (0), then at 2, 4, 6 and 8 hours post choline consumption. During V2, participants were given a standardised low-choline breakfast and lunch (total choline intake $<50 \mathrm{mg}$ ) (8), between 0-2 and 4-6 hours respectively. This protocol was approved by the local ethics committee and adhered to the Declaration of Helsinki. All participants provided written informed consent. Plasma samples were quantified in duplicate for TMAO, using stable isotope dilution liquid chromatography-tandem mass spectrometry (LC-MS/MS) on a Shimadzu LC-30AD coupled with an 8050 triple quadruple mass spectrometer (TQ-MS), using an optimised version of a previously described method (9), with a run time of 1 minute and limit of quantification (LOQ) of $0.1 \mu \mathrm{mol} / \mathrm{L}$. Individual responses of circulating TMAO levels in participants are shown in Figure 1a. 
Participants showed a range in circulating TMAO levels between $0-20 \mu \mathrm{mol} / \mathrm{L}$ over the 8 hour period, with a few $(n=4)$ showing higher TMAO levels following six hours post-choline consumption $(>20 \mu \mathrm{mol} / \mathrm{L})$. We observed that there were patients that showed raised TMAO levels in response to choline loading ('responders') and those that did not ('non-responders'). To further investigate the different responses to choline loading (response vs non-response), participants were split according to the median baseline TMAO level of $2.0 \mu \mathrm{mol} / \mathrm{L}$ (Figure 1b), into high TMAO (HT) and low TMAO (LT) groups. TMAO levels rapidly and significantly increased from 4 hours after choline loading in the HT group; in contrast, TMAO levels showed no change at any time point after choline loading in the LT group (Figure 1b) $(\mathrm{p}=0.012)$. TMAO levels in the HT group were higher than those in the LT group at all times during the acute oral choline challenge (3.1-16.3 $\mu \mathrm{mol} / \mathrm{L}$ vs. 1.3-3.3 $\mu \mathrm{mol} / \mathrm{L}$, respectively). Participants in the HT group ( $n=9)$ tended to be older and had higher alcohol intake compared to those in the LT group ( $\mathrm{n}=9$ ); however this was not statistically significant ( $\mathrm{p}=0.094$ and $\mathrm{p}=0.063$, respectively). Gender, ethnicity, BMI, and weekly physical activity were similar between groups $(\mathrm{p}>0.05)$. Dietary records from the two weeks prior to acute choline loading as well as baseline records did not show any differences in TMA rich food intake (red meat, eggs or fish) between groups (Table 1). No side effects (e.g. fishy body odour) were reported during the study.

The present study indicates that acute choline loading in healthy subjects produces a differential response in circulating TMAO levels (i.e. 'responders' and 'non-responders'). These two different response groups in TMAO production following choline challenge were demonstrated for the first time by the present study. To note, individuals with a 'responder' phenotype had higher baseline TMAO levels. Furthermore, food diaries from these individuals, assessed to determine protein intake in the two weeks before choline loading, showed no significant differences in TMA rich foods (e.g. red meat, eggs) compared to those with a 'non- 
responder' phenotype. This indicates that omnivorous individuals can have different responses to dietary sources of choline, independently of daily dietary conditions. TMAO levels were also analysed for association with participants' physical activity due to the beneficial effect of physical activity on cardiovascular risk, in particular when combined with dietary intervention (10). We did not observe differences in TMAO levels with respect to physical activity between the low and high TMAO groups. In previous studies, acute dietary supplementation of choline has been shown to increase TMAO levels in a general population (11). However, most studies have focused on carnitine, demonstrating the effect of L-carnitine supplementation with increased TMAO levels correlated to chronic carnitine intake (12). TMAO levels have been attributed more to carnitine rather than choline and from red meat rather than other sources of protein (13). Whilst these studies showed that TMAO levels are significantly increased with L-carnitine and red meat intake, they did not account for baseline differences in the TMAO levels of participants and whether these could affect subsequent TMAO increase, underlying a responder or non-responder phenotype. Further, single TMAO time point cross-sectional studies are unable to ascertain whether there are temporal or individual differences in TMAO production, following dietary/loading challenge (e.g. response). The current study sheds light upon the hypothesis that individuals respond differently to dietary choline intake, which could be related to reduced FMO3 activity or gut bacterial conversion of choline to TMA, resulting in inefficient conversion of choline to TMAO. Further investigation of gut microbial composition and FMO3 activity to identify outstanding factors for response to choline loading is warranted.

In conclusion, our findings suggest the presence of different TMAO responses to acute choline loading. As a current goal of cardiovascular disease prevention is to target lifestyle factors (14), with dietary manipulation (e.g. to reduce red meat consumption) being one of the mainstays for intervention, the finding that not all subjects respond uniformly to dietary choline 
intake, and the use of a loading test to identify 'responders/non-responders' might help to further stratify patients into appropriate dietary interventions. Further studies that address whether the 'responder' phenotype affords a higher risk for cardiovascular risk, and can be used to identify patients warranting dietary intervention are needed.

\section{Acknowledgements}

TS receives grant support from the Leicester Drug Discovery and Diagnostics (LD3) MRC Confidence in Concept $(\mathrm{CiC})$ award in collaboration with ADM Protexin Ltd. (formerly Probiotics International Ltd.).

\section{Conflicts of Interest.}

The authors declare that they have no conflict of interest.

\section{Author Contribution}

TS contributed to the conception, design, data analysis and interpretation of the work and critically revised the manuscript. SC and AS contributed to conduction of the study, data analysis, interpretation of the work, drafted the manuscript and critically revised the manuscript. YY contributed to conduction of the study, data analysis, and critically revised the manuscript. DB, MW, and MZI contributed to the acquisition of data for the work and critically revised the manuscript. LMH contributed to the conception and design of the study, and critically revised the manuscript. All authors gave final approval and agree to be accountable for all aspects of the work ensuring integrity and accuracy. 


\section{References}

(1) Estruch R, Ros E, Salas-Salvadó J, Covas MI, Corella D, Arós F, et al. Primary Prevention of Cardiovascular Disease with a Mediterranean Diet Supplemented with Extra-Virgin Olive Oil or Nuts. N Engl J Med 2018 Jun 21;378(25):e34.

(2) Wang Z, Tang WW, Buffa JA, Fu X, Britt EB, Koeth RA, et al. Prognostic value of choline and betaine depends on intestinal microbiota-generated metabolite trimethylamine- $\mathrm{N}$-oxide. Eur Heart J 2014 Apr;35(14):904-10.

(3) Schuett K, Kleber ME, Scharnagl H, Lorkowski S, März W, Niessner A, et al. Trimethylamine-N-oxide and heart failure with reduced versus preserved ejection fraction. $\mathbf{J}$ Am Coll Cardiol 2017 Dec 26;70(25):3202-3204.

(4) Suzuki T, Yazaki Y, Voors AA, Jones DJ, Chan DC, Anker SD, et al. Association with outcomes and response to treatment of trimethylamine $\mathrm{N}$-oxide in heart failure (from BIOSTAT-CHF). Eur J Heart Fail 2018 Oct 29.

(5) Suzuki T, Heaney LM, Bhandari SS, Jones DJ, Ng LL. Trimethylamine N-oxide and prognosis in acute heart failure. Heart 2016 Jun 1;102(11):841-8.

(6) Trøseid M, Ueland T, Hov J, Svardal A, Gregersen I, Dahl C, et al. Microbiota-dependent metabolite trimethylamine-N-oxide is associated with disease severity and survival of patients with chronic heart failure. J Intern Med 2015 Jun;277(6):717-26.

(7) Bennett B, Vallim T, Wang Z, Shih D, Meng Y, Gregory J, et al. Trimethylamine-N-Oxide, a Metabolite Associated with Atherosclerosis, Exhibits Complex Genetic and Dietary Regulation. Cell Metab. 2013 Jan 8;17(1):49-60. 
(8) Busby MG, Fischer L, Da Costa K, Thompson D, Mar M, Zeisel SH. Choline-and betainedefined diets for use in clinical research and for the management of trimethylaminuria. $\mathrm{J}$ Am Diet Assoc. 2004 Dec;104(12):1836-45.

(9) Heaney LM, Jones DJ, Mbasu RJ, Ng LL, Suzuki T. High mass accuracy assay for trimethylamine $\mathrm{N}$-oxide using stable-isotope dilution with liquid chromatography coupled to orthogonal acceleration time of flight mass spectrometry with multiple reaction monitoring. Anal Bioanal Chem. 2016 Jan;408(3):797-804.

(10) Alvarez-Alvarez I, Zazpe I, de Rojas JP, Bes-Rastrollo M, Ruiz-Canela M, FernandezMontero A, et al. Mediterranean diet, physical activity and their combined effect on all-cause mortality: The Seguimiento Universidad de Navarra (SUN) cohort. Prev Med 2018 Jan;106:4552.

(11) Tang WW, Wang Z, Levison BS, Koeth RA, Britt EB, Fu X, et al. Intestinal microbial metabolism of phosphatidylcholine and cardiovascular risk. N Engl J Med 2013 Apr 25;368(17):1575-84.

(12) Koeth RA, Lam-Galvez BR, Kirsop J, Wang Z, Levison BS, Gu X, et al. L-Carnitine in omnivorous diets induces an atherogenic gut microbial pathway in humans. J Clin Invest 2019 Jan 2;129(1):373-387.

(13) Wang Z, Bergeron N, Levison BS, Li XS, Chiu S, Jia X, et al. Impact of chronic dietary red meat, white meat, or non-meat protein on trimethylamine N-oxide metabolism and renal excretion in healthy men and women. Eur Heart J 2018 Dec 10.

(14) Piepoli MF, Hoes AW, Agewall S, Albus C, Brotons C, Catapano AL, et al. 2016 European Guidelines on cardiovascular disease prevention in clinical practice: The Sixth Joint 
Task Force of the European Society of Cardiology and Other Societies on Cardiovascular Disease Prevention in Clinical Practice (constituted by representatives of 10 societies and by invited experts) Developed with the special contribution of the European Association for Cardiovascular Prevention \& Rehabilitation (EACPR). Eur J Prev Cardiol. 2016 Jul;23(11):NP1-NP96. 
Table 1. Demographics data from the participants assessed for this study.

\begin{tabular}{|c|c|c|c|c|}
\hline & $\begin{array}{l}\text { Total } \\
(n=18)\end{array}$ & $\begin{array}{l}\text { low TMAO } \\
(\leq 2.0 \mu \mathrm{mol} / \mathrm{L})\end{array}$ & $\begin{array}{l}\text { high TMAO } \\
(>2.0 \mu \mathrm{mol} / \mathrm{L})\end{array}$ & p value \\
\hline \multicolumn{5}{|l|}{ Demographics } \\
\hline Age & $28[23-36]$ & 25 [21-29] & 33 [27-49] & 0.094 \\
\hline Male & $5(28 \%)$ & $1(11 \%)$ & $4(44 \%)$ & 0.294 \\
\hline Caucasian & $14(78 \%)$ & $7(78 \%)$ & $7(78 \%)$ & 1.000 \\
\hline BMI & 21.7 [20.9-23.8] & 20.9 [20.2-23.8] & $22.6[21.5-23.7]$ & 0.258 \\
\hline Current smoker & $1(6 \%)$ & $0(0 \%)$ & $1(11 \%)$ & 1.000 \\
\hline FH of CVD & $3(17 \%)$ & $2(22 \%)$ & $1(11 \%)$ & 1.000 \\
\hline $\begin{array}{l}\text { Systolic blood pressure } \\
(\mathrm{mmHg})\end{array}$ & 117 [110-129] & 118 [110-124] & 116 [115-133] & 0.666 \\
\hline $\begin{array}{l}\text { Diastolic blood } \\
\text { pressure }(\mathrm{mmHg})\end{array}$ & 78 [74-86] & 78 [70-86] & 77 [76-82] & 0.863 \\
\hline Heart rate (beats/min) & $68[63-78]$ & $65[65-76]$ & $70[62-78]$ & 0.605 \\
\hline $\begin{array}{l}\text { Physical Activity } \\
\text { (days/week) }\end{array}$ & $3.5[2.5-7]$ & $4.0[2.5-7]$ & $3.0[3-7]$ & 0.876 \\
\hline \multicolumn{5}{|l|}{ Intake history } \\
\hline $\begin{array}{c}\text { Alcohol } \\
\text { (units/week) }\end{array}$ & $1[0-3]$ & $0[0-0.1]$ & $2[1-6]$ & 0.063 \\
\hline Red meat (units/week) & $3[1-4]$ & $2[1-3]$ & 3 [3-4] & 0.258 \\
\hline Fish (units/week) & $1[1-3]$ & $1[0.1-3]$ & $2[1-2]$ & 0.489 \\
\hline Eggs (units/week) & $1[1-3]$ & $1[1-2]$ & $2[1-4]$ & 0.297 \\
\hline \multicolumn{5}{|l|}{ Laboratory } \\
\hline Cholesterol (g/dL) & $4.7[4.0-5.2]$ & $4.6[4.4-5.2]$ & $4.7[3.9-5.2]$ & 0.796 \\
\hline HDL (g/dL) & $1.6[1.4-1.9]$ & $1.5[1.4-1.7]$ & $1.9[1.4-2.0]$ & 0.546 \\
\hline \multicolumn{5}{|l|}{ TMAO $(\mu \mathrm{mol} / \mathrm{L})$} \\
\hline Baseline & $2.0[1.3-4.0]$ & $1.3[0.7-1.6]$ & $4.0[3.3-5.9]$ & $<0.001 *$ \\
\hline \multicolumn{5}{|l|}{ After choline loading } \\
\hline 0 hour & $2.1[1.4-3.4]$ & $1.5[1.3-1.9]$ & $3.4[2.2-3.5]$ & $0.024 *$ \\
\hline 2 hours & $2.0[1.3-3.1]$ & $1.3[1.2-2.0]$ & $3.1[2.0-4.0]$ & $0.021 *$ \\
\hline 4 hours & $1.9[1.2-4.5]$ & $1.3[1.1-1.8]$ & $4.5[2.7-6.5]$ & $0.001 *$ \\
\hline 6 hours & $4.1[1.0-10.3]$ & $1.0[0.8-1.9]$ & $10.3[7.3-34.0]$ & $0.001 *$ \\
\hline 8 hours & $6.6[4.4-16.3]$ & $3.3[1.0-6.2]$ & $16.3[11.6-50.5]$ & $0.001 *$ \\
\hline
\end{tabular}

Analysed data were split into high and low TMAO groups (HT and LT groups respectively), based on the median of baseline values. Mann-Whitney U test for continuous variables and chi-squared test for categorical variables were used to examine between-group differences. Subsequent analyses used a general linear model with repeated measures and Bonferroni correction to compare group TMAO means during the oral acute choline challenge. $\mathrm{P}$ values $<0.05$ were deemed statistically significant. IBM SPSS Statistics (v25, IBM Corp., Armonk, NY, USA) and Prism (v.7, GraphPad) were used.

BMI: Body mass index; FH: familiar history; CVD: cardiovascular diseases; TMAO: trimethylamine N-oxide; HDL: high density lipoprotein. $* \mathrm{P}<0.05$ 
Figure 1. (a) Plasma TMAO levels over an 8 hour period following acute choline loading of $700 \mathrm{mg}$ orally after 0 hours (arrow). (b) Participants were split into two groups dependent on the median TMAO levels at baseline (high or low TMAO).
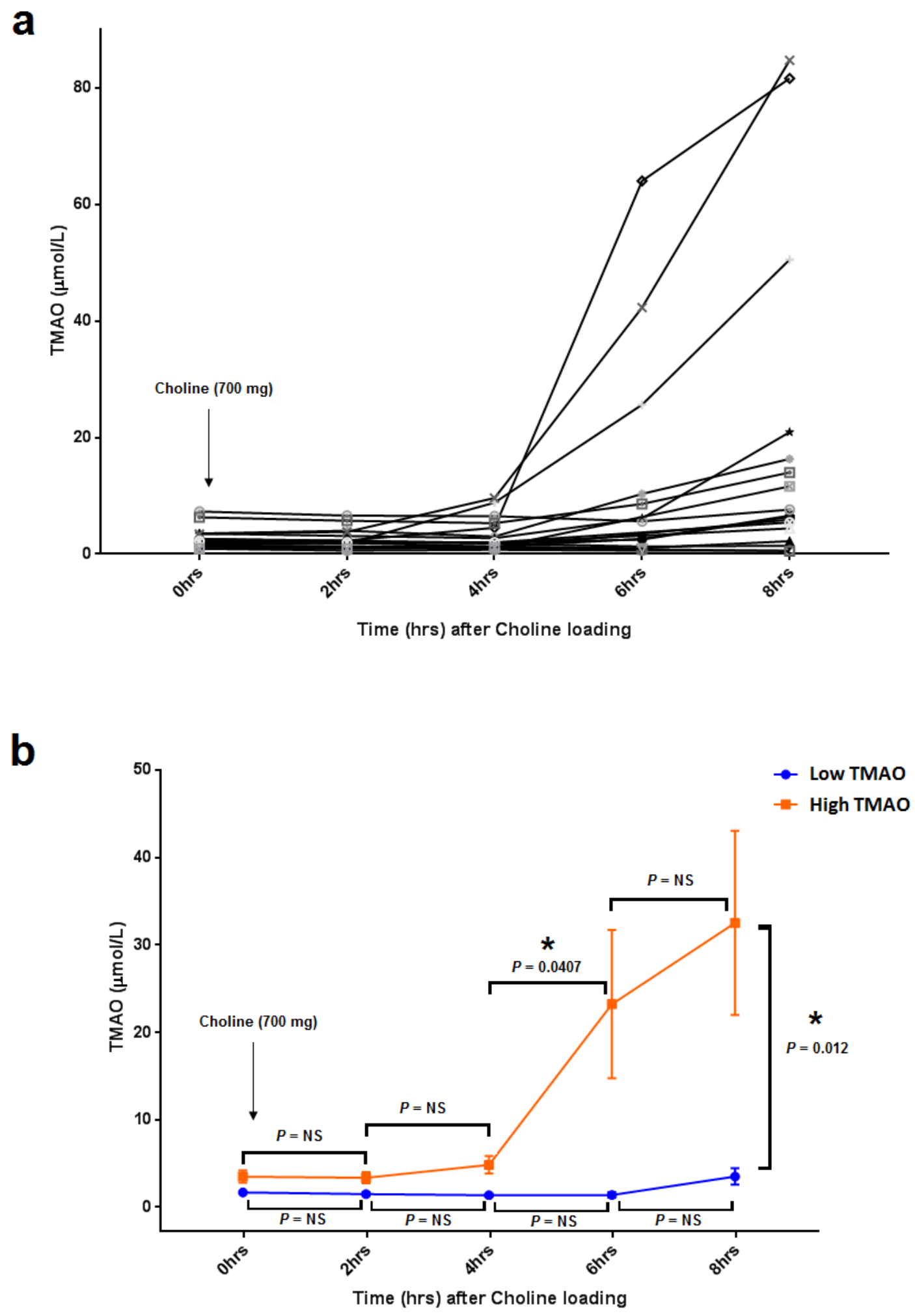

Data are presented as the mean \pm SEM. NS: non-significant. $* \mathrm{P}<0.05$ 